\title{
Identification Features of External and Internal Variables in the Mathematical Model of Educational Trajectory
}

\author{
Krupa Tatiana
}

\begin{abstract}
The article describes the main stages of identification and formation of variables which are included in the developed mathematical model of the student's educational trajectory. Analyzed are such groups of external variables as geographical location, age and gender, learning style and parameters of user interaction with the user interface, academic performance, level of possession of complex skills. The numerical values of the variables in different conditions are determined. The types of sessions in which information is collected are highlighted. Data arrays from such information sources as the GlobalLab online platform and the electronic diary Diary.ru were analyzed. Using the studied variables, a mathematical model of the student is presented, which takes into account many properties. The aim of the project is to create a technological model for the application of machine learning methods to predict the optimal educational trajectory of the student. Achieving this goal and using the scientific and technical results of the Project will provide a number of useful technical, technological and technical and economic effects.
\end{abstract}

Keywords: mathematical model, machine learning, online training, GlobalLab, educational trajectory

\section{INTRODUCTION}

The use of machine learning methods for the formation of personal educational paths through full or partial automation will significantly reduce the cost of individualization of training, which, as many domestic and foreign pedagogical studies show, has a positive effect on the level of educational results.

The development of skills

Nowadays, teachers need the minimum skills to incorporate technology into teaching: They must have at least a minimum of hardware and software skills and equipment in an advanced engineering school. In addition to the minimum number, teachers need a full range of support, such as design and planning, instructional design, the equipment or equipment listed above, or complete skills that often require an unreasonable amount of time, money and effort to gain

Revised Manuscript Received on February 05, 2020.

* Correspondence Author

Krupa Tatiana*, GlobalLab, LLC, Moscow, Russia. Email: krupa.tatiana@mail.ru

(C) The Authors. Published by Blue Eyes Intelligence Engineering and Sciences Publication (BEIESP). This is an open access article under the CC BY-NC-ND license (http://creativecommons.org/licenses/by-nc-nd/4.0/) time, money and effort. they further aggravate other professional activities that are rewarded in the job and promotion process. The types of support that CU-Boulder should provide for the effective and widespread use of training techniques include:

- Planning instructions;

- Media production;

- Learning management systems;

- Facilities and equipment.

Support can take many forms: traditional support or desk, short-term or long-term counseling and training. Many campus units currently provide one or more types of support, and they do not understand what the unit does, for whom, and with what efficiency. Support and training for all training technologies should be closely integrated into existing teacher and assistant development programs. The campus should continue to provide educational technology when the faculty or department wants the service unit to perform its function by supporting media education or research [13]. Most teachers use technology to improve or facilitate the organization and management of courses by posting training programs on the course website or by displaying Power Point slides instead of overhead and transparent materials. There is little or no change in this way of use in educational practice, and they are often translated into new media with greater efficiency. Faculties receive different support services for different technologies: production and design support for basic website development, equipment support and classroom equipment. Support for learning management systems also facilitates the use of this educational technology. Some teachers use technology in ways that require strong design support. In other words, they are changing teaching methods to fit existing and emerging technologies. For example, a teacher may create an interactive three-dimensional Java program to demonstrate it scientifically.

\section{METHODOLOGY}

Arrays of data from the GlobalLab online platform and the electronic diary Diary.ru were used to form a model of the student's educational trajectory. The methodology of mathematical modeling, analysis and selection of variables was used. In the work, types of sessions were formed to collect information about students, and for each type of sessions, the values of variables averaged over all sessions were clustered using the k-means method. 
For mathematical modeling, Jupyter Notebook, GNU Octave software was used.

By configuring machine learning models to take into account each participant profiles, recommendations can be made to create the most efficient teams and hence produce the best results.

When working on literature, the key was to explore the possibility of developing online math courses in line with the ideas presented in the introduction.

Literature can be divided into the following sections:

1) research into the technique of identifying learning;

2) research that explores methods for creating personalized training practices for online courses;

3) studies looking at the aspect of individualization in the context of specific features of mental health processes;

4) studies on the social and humanities of online education;

5) a study on the technical aspects of creating and delivering online courses $[11,12]$.

\section{RESULT AND DISCUSSION}

At Stage 1 of the applied scientific research (ASR), all the variables used in mathematical modeling of both the subject and the object of the educational path were proposed to be divided into two main clusters:

1) a cluster of external variables;

2) a cluster of internal variables.

External variables include variables that describe the student's properties, independent of the Stage within the educational path. Such properties, in particular, include gender, learning style, student age. External variables and methods for calculating their values are a mathematical model of a student as a subject of an educational trajectory. In this regard, at Stage 2 of the ASR, as part of the solution to the problem of developing a mathematical model of a student, researchers needed to:

1) Consider a list of hypothetical external variables whose values can be obtained from data sources available to researchers (data from the GlobalLab platform, data from the electronic diary Diary.ru).

2) Determine the number of students for whom data are available for each hypothetical external variable.

3) Determine the possibility and method of restoring or modeling the values of a hypothetical external variable if its value cannot be obtained directly from data sources.

4) Make a decision to include a hypothetical external variable in the final list of variables included in the student's mathematical model.

5) If you include a variable in the final list, set the method for calculating the value of the variable based on the source data.

At Stage 1 of the ASR, the groups presented in Table 1 were included in the cluster of external variables [1].

Table 1. Groups of external variables highlighted in Stage 1

\begin{tabular}{|l|l|l|}
\hline No. & Group of variables & $\begin{array}{l}\text { Planned } \\
\text { number } \\
\text { of variables } \\
\text { in the group }\end{array}$ \\
\hline 1 & Geographical position & $2-3$ \\
\hline 2 & Age and gender & 2 \\
\hline 3 & Learning style and user interaction parameters & $4-6$ \\
\hline
\end{tabular}

\begin{tabular}{|l|l|c|}
\hline 4 & Academic performance (grades, test results) & $1-5$ \\
\hline 5 & Level of proficiency in complex skills & $1-5$ \\
\hline
\end{tabular}

At Stage 2 of ASR, hypothetical variables of all 5 groups were analyzed. Below is the progress and results of the analysis of each of the groups.

To give a mathematical model of an educational trajectory of a finished form, the concept of time must be introduced into it. The trajectory consists of events (states), not just following each other, but also having two very important temporal characteristics: duration and interval.

Duration indicates how long a particular state of the trajectory lasted, while the interval reflects how far this state is from the previous one. In order to unify these two characteristics, it was proposed to represent the period of the absence of any event in the trajectory as an event of a special type - an inactivity event. Thus, the duration becomes another characteristic of the state of the trajectory, and the interval is such a characteristic for the inactivity event.

In accordance with given the representation of the events of the educational trajectory, the hypothesis takes the form of $(1,2)$ :

$$
\begin{gathered}
\mathrm{x}_{\mathrm{t}}=\left\{\mathrm{e}_{\mathrm{t}}, \mathrm{d}_{\mathrm{t}}\right\} \\
\mathrm{h}_{\mathrm{t}}=\mathrm{f}\left(\mathrm{ht}_{-1}, \mathrm{x}_{\mathrm{t}} ; \theta\right)
\end{gathered}
$$

where $d_{t}$ is the duration of the condition described by $e_{t}$.

To include the characteristics of the continuing time $d_{t}$ in the mathematical model of the educational trajectory, an event contextualization method was proposed.

In the framework of modeling the characteristics of the duration of the state of the educational trajectory, the vector of the temporary context $c^{\mathrm{d}}$ is calculated first (3):

$$
c^{d}=\varphi\left(\log \left(d_{t}\right) ; \theta\right)
$$

where $\varphi$ is the nonlinear transformation dt performed by the direct propagation method in a neural network with a set of parameters $\theta$.

The logarithmic transformation $d_{t}$ is performed in order to smooth out a wide range of values expressing time intervals and to make possible the simultaneous use of periods expressed in days, months, and even years [9].

The calculation of the time mask vector is carried out by linear transformation $\mathrm{c}^{\mathrm{d}}$ using a set of weights $\mathrm{W}_{\mathrm{d}} \in \mathrm{R}^{\mathrm{CxE}}$ and offsets $b_{d} \in \mathbb{R}^{E}$. The result of the transformation is then transferred to the sigmoidal nonlinear activation function $\sigma$ to obtain the mask $\mathrm{m}_{\mathrm{d}} \in \mathbb{R}^{\mathrm{E}}$ and $\mathbb{R}^{\mathrm{E}} \rightarrow[0 ; 1]$ (4). $\mathrm{C}$ is the dimension of the vector of the temporary context, $\mathrm{E}$ is the dimension of the vector of embedding the state of the educational trajectory.

$$
m_{d}=\sigma\left(c^{d} W_{d}+b_{d}\right)
$$

The resulting vector of the temporary mask is then superimposed on the vector of embedding the state of the educational trajectory by applying the operation of the element-wise product (5):

$$
\mathrm{q}_{\mathrm{t}} \leftarrow \mathrm{x}_{\mathrm{t}} \odot \mathrm{m}_{\mathrm{d}}
$$

The resulting vector, in turn, is input to the recursive layer of the RNS. Thus, the vector qt, which simulates one Stage of the educational path, is used as input for the mathematical model of using the XMANN recurrence network developed in Stage 1 of the ASR [1].

Published By:

Blue Eyes Intelligence Engineering

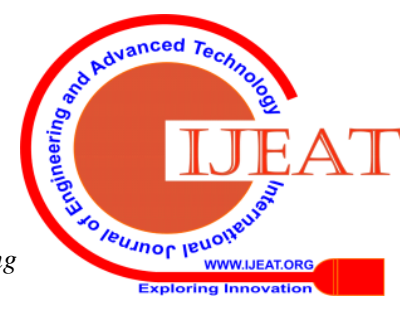



trajectory change over time, it can be characterized as dynamic. Due to the use of nonlinear transformations in presenting the characteristics of the duration of the state of the educational trajectory (4) and the sigmoidal function of nonlinear activation, the calculation of the time mask vector (5) is a non-linear model of the educational trajectory. When calculating the time mask vector, a set of weights $\mathrm{W}_{\mathrm{d}}$ is applied, which are initialized by random variables, which determines the stochastic nature of the model.

According to the way of representing the object of modeling, the model of the educational trajectory is functional for the reasons already described above in relation to the student's model.

At Stage 2 of the ASR, a final list of events is formed, which are taken into account by the mathematical model of the educational trajectory. The list of events allows us to increase the adequacy of the mathematical model of the educational trajectory by including in it a wide range of educational activities that are not traditionally included in student models [4-7].

These assessments can offer potential educational decisions on the quality of learning outcomes and ensure equity in the allocation of learning opportunities. Thus, learning the trajectory of learning experiences would support policy goals, set measurable goals, assist and even reform the appropriate education system. In addition, benchmarking will help countries to better understand the risks and challenges of student learning, to explore their relative strengths and weaknesses, and to monitor progress.

This facilitates the ability to correlate outcomes with learning goals, in addition to the proposed innovative approach that reflects students' abilities and considers how these skills relate to adulthood [2].

Defining the path of learning and learning, van den Hevel-Panhuizen (2008) notes that there are three intertwined meanings: a learning trajectory that gives an overview of the student learning process and a learning trajectory consisting of didactic features that describe how it can best integrate and encourage the learning process and syllabus, indicating which of the major elements of the mathematics curriculum should be taught.

Van den Heuvel-Panhuizen describes how the "learning-to-learn" (TAL8) trajectory, with transitional goals in primary schools, is based on early numerical experiences for children. They represent TAL numbers for the youngest children on three levels. The first level is called the "Emergency number" (pre-school year), the second is the "Increasing sense of number" (kindergarten 1 and 2), and the third - "Calculations up to 20" (1st and 2nd grade) [14, 17]. Further discussion of the importance of this work, as it relates to numbers, geometry and dimensions. The intention is to extend this work to secondary education. The learning and learning trajectory are seen as part of the "longitudinal perspective" all teachers must adhere to. It is seen that it goes beyond the textbook and beyond the tests, but focuses on achievement goals and the overall learning activity that can contribute to their achievement. In particular, "level" understanding of domains is considered as potentially useful for indicating utility paths, i.e. [15, 18, 19].

Those relate to particular school years or grades. They are
Since the input variables of the model of the educational

also seen as useful in raising the level that is, directing children towards the final basic goals of basic mathematics education. It is also suggested that publicly available curricula offer teachers a way to control children's development [3].

\section{AI projections on the path of student learning}

Artificial intelligence in schools will enable students to analyze students' abilities and performance and point ahead with predictive analytics [8].

Some developers are currently developing machine learning prediction models to achieve this. For example, if student letter scores are constantly declining, the program can predict how it will behave in the future if the student does not take appropriate action. Then the teacher can look for other ways of adapting, directing, or helping students better [13, $16,20]$.

Table 2. Qualities of learning trajectories (left) and mis-perceptions (right) [10]

\begin{tabular}{|c|c|}
\hline What Learning Trajectories Are & $\begin{array}{c}\text { What Learning Trajectories } \\
\text { Are Not }\end{array}$ \\
\hline Domain-specific models & General or universal principles \\
\hline $\begin{array}{c}\text { Expected probabilities } \\
\text { Stuge theories } \\
\text { student thinking }\end{array}$ & $\begin{array}{c}\text { Logico-mathematical } \\
\text { deconstructions }\end{array}$ \\
\hline $\begin{array}{c}\text { Based in students' thinking } \\
\text { mathematics }\end{array}$ & $\begin{array}{c}\text { Based in opinions of experts in } \\
\text { mathercises }\end{array}$ \\
\hline Elicited by rich or novel tasks & Derived from typical exercisen \\
\hline $\begin{array}{c}\text { Include strategies, reasons, } \\
\text { explanations and cases }\end{array}$ & $\begin{array}{c}\text { Sub-goals of the target Include } \\
\text { exploring misconceptions }\end{array}$ \\
\hline A means to avoid errors & Ordered by difficulty \\
\hline $\begin{array}{c}\text { Ordered by increasing } \\
\text { sophistication }\end{array}$ & Curriculum material \\
\hline $\begin{array}{c}\text { Connected to big ideas over the } \\
\text { long term }\end{array}$ & Fixed \\
\hline Evolving &
\end{tabular}

\section{CONCLUSION}

At Stage 2 ASR, a mathematical model of the educational trajectory is developed, which includes:

- external variables that reflect the student's properties, including student learning outcomes;

- internal variables that reflect the basic properties of the Stage of the educational trajectory at the time of each event in it;

- temporal characteristics expressing the duration and intervals of Stages that make up the educational trajectory, and thus reflecting their structure.

Based on the results of work, it can be concluded that the mathematical model of the student (subject of the educational trajectory) was successfully formed, which included a total of 43 variables that reflect the following basic properties of students:

- geographical location, including the accessibility of cultural and educational facilities and indirect reflection of climatic conditions (3 variables);

- $\quad$ gender and age (3 variables);

- parameters of user interaction with the user interface (25 variables);

- $\quad$ the style of his training (4 variables); 
- $\quad$ academic results, including weighted average grades in subjects of various profiles and test results taking into account the time taken to complete the assignment (6 variables);

- the development of complex skills of both the student himself and, in some cases, his teacher (2 variables).

\section{ACKNOWLEDGMENT}

Applied research described in this paper is carried out with financial support of the state represented by the Ministry of Science and Higher Education of the Russian Federation under the Agreement \#14.576.21.0100 of 26 September 2017 (unique identifier of applied research RFMEFI57617X0100).

\section{REFERENCES}

1. T. V. Krupa, Theoretical studies of the performed for the Stages of the ASR tasks. Moscow: GlobalLab, LLC, 2018.

2. L. Furukawa, "Trajectory of Learning Experience based on the Performance of Canada's Youth in Mathematics", International Journal of Innovation in Science and Mathematics Education, 26(6), 62-75, 2018.

3. E. Dunphy, T. Dooley, Gerry Shiel (Eds.), Mathematics in Early Childhood and Primary Education (3-8 years) Definitions, Theories, Development and Progression. Dublin: National Council for Curriculum and Assessment, 2014.

4. OECD. (2013). PISA 2012 Assessment and analytical framework: Mathematics, reading, science, problem solving and financial literacy. Paris: OECD Publishing.

5. OECD (2014a). PISA 2012 Results: What students know and can do. Student Performance in Mathematics, Reading and Science, 1, Paris: OECD Publishing. DOI: 10.1787/9789264208780-en

6. OECD (2014b). A Profile of student performance in mathematics, in PISA 2012 Results: What Students Know and Can Do (Volume I, Revised edition, February 2014): Student Performance in Mathematics, Reading and Science, OECD Publishing, Paris. DOI: 10.1787/9789264208780-6-en

7. OECD (2014c). Mathematics performance (PISA) (indicator). DOI: 10.1787/04711c74-en

8. "Mathematical Modelling in Science and Technology", In Xavier J.R. Avula, Rudolf E. Kalman, et al. (eds.), The Fourth International Conference, Zurich, Switzerland, August 1983, Pergamon, 1984. https://doi.org/10.1016/C2013-0-06067-7

9. I. Azam, M. A. Hasan, T. Abbasi, S. Ahmed, M. Abbasi, "Education Technology Based Models of Teaching and Learning", Proceedings of the 4th National Conference; INDIACom-2010 Computing For Nation Development, February 25 - 26, 2010 Bharati Vidyapeeth's Institute of Computer Applications and Management, New Delhi, 2010.

10. M. Taguma, F. Gabriel, M. H. Lim, "Future of Education and Skills 2030: Curriculum analysis A Synthesis of Research on Learning Trajectories/Progressions in Mathematics", OECD. Organisation for Economic Co-operation and Development EDU/EDPC(2018)44/ANN3, $2019 . \quad$ Retrieved from https:/www.oecd.org/education/2030-project/about/documents/A_Synt hesis_of_Research_on_Learning_Trajectories_Progressions_in_Mathe matics.pdf

11. D. Mitchell, Education that fits: Review of International trends in The education of students with special educational needs. University of Cambridge, 2015.

12. L. Konnova, L. Lipagina G. Postovalova A. Rylov I. Stepanyan, "Designing Adaptive Online Mathematics Course Based on Individualization Learning”, Education Sciences, 9 (3):182, 2019. DOI: 10.3390/educsci9030182

13. G. Dogra, "Machine Learning and the Future of Education", $A I$ Business. Retrieved from https://aibusiness.com/machine-learning-and-the-future-of-education/

14. D. Sharma, "Artificial Intelligence and Big Data in Higher Education: Promising or Perilous?", SmartDataCollective. Retrieved from https://www.smartdatacollective.com/artificial-intelligence-and-big-dat a-in-higher-education-promising-or-perilous/

15. P. Gardner, C. Rix, "Learning Trajectories of Primary Student Teachers; a Cross-Cultural Comparison", Journal of Social Sciences, 8 (2): 135-142, 2012.

6. O. V. Makhnytkina, Modeling and optimization on an individua trajectory of an ordinary student: Abstract thesis. Novosibirsk, 2013.

17. O. A. Granichina, "Mathematical models of the quality control of the educational process in the university with active optimization", Stokhaisticheskaya optimizatsiya v informatike, 2: 77-108, 2006. Retrieved from https://www.math.spbu.ru/user/gran/sb2/granolga.pdf

18. P. Sztajn, J. Confrey, P. H. Wilson, C. Edgington, "Learning Trajectory Based Instructions: Toward a Theory of Teaching", Educational Researcher, 41 (5): 147-156, 2012. Retrieved from https://www.jstor.org/stable/23254092?seq=1

19. E. Merzon, E. Galimullina, E. Ljunimova, "A smart trajectory model for teacher training", In Cases on Smart Learning Environments (pp. 164-187), 2019. DOI: 10.4018/978-1-5225-6136-1.ch010

20. P. V. Ovchinnikov, Mathematical Models and Instruments for Designing Adaptive Educational Trajectories for Preparation of Competitive Specialists in Universities: Abstract thesis. Rostov-on-Don, 2014. Retrieved from http://economy-lib.com/matematicheskie-modeli-i-instrumentariy-proe ktirovaniya-adaptivnyh-obrazovatelnyh-traektoriy-dlya-podgotovki-ko nkurentosp 